\title{
Artificial Pinning Center Nb-Ti Superconductors with Alloyed Nb Pins
}

\author{
Robert W. Heussner, Cristina Bormio Nunes, ${ }^{*}$ Lance D. Cooley and David C. Larbalestier \\ Applied Superconductivity Center, University of Wisconsin-Madison, WI 53706 \\ *on leave from Faenquil/Demar, 12600-000 Lorena SP, BRAZIL
}

\begin{abstract}
A magnetic interaction has been proposed as the dominant fluxon-defect interaction in conventional and artificial pinning center (APC) $\mathrm{Nb}-\mathrm{Ti}$, emphasizing the proximity length $\left(\xi_{N}\right)$ of the pinning center as the important parameter for optimizing the high field critical current density. We have characterized APC composites containing 25 vol. \% of $\mathrm{Nb}$ pins alloyed with $7.5 \mathrm{wt} . \% \mathrm{Ta}$ and $10 \mathrm{wt} . \% \mathrm{~W}$ to deliberately test the predictions of this model. We found that the bulk flux pinning force of the Nb10W-pin composite $\left(\xi_{N}(N b 10 W)-32 \mathrm{~nm}\right)$ exhibited a magnetic field $(H)$ and pin size $\left(d_{p}\right)$ dependency that is more consistent with conventionally processed $\mathrm{Nb} 47 \mathrm{Ti}\left(\xi_{N}(\alpha-\right.$ Ti) $<32 \mathrm{~nm}$ ) than with existing pure $\mathrm{Nb}$-pin APC composites $\left(\xi_{\mathrm{N}}(\mathrm{Nb}) \sim 83 \mathrm{~nm}\right)$. The Nb7Ta-pin composite $\left(\xi_{\mathrm{N}^{N}}-59 \mathrm{~nm}\right)$ had intermediate $F_{p}\left(H, d_{p}\right)$ behavior, thus qualitatively supporting the model.
\end{abstract}

\section{INTRODUCTION}

Artificial pinning center (APC) Nb-Ti superconducting wires have demonstrated superior flux pinning properties compared to conventionally processed wires. APC wires with 24 and 28 volume percent of nominally round [1] or planar [2] $\mathrm{Nb}$ pins have produced bulk flux pinning forces $\left(\mathrm{F}_{\mathrm{p}}\right)$ in excess of $30 \mathrm{GN} / \mathrm{m}^{3}$ at $4.2 \mathrm{~K}$, far surpassing the $18 \mathrm{GN} / \mathrm{m}^{3}$ [3] achieved in optimized, conventional wires, for which the flux pinning microstructure consists of $\sim 20$ vol.\% of $1-2 \mathrm{~nm}$ thick $\alpha$-Ti ribbons [4], [5]. However, the reduced magnetic field $\left(\mathrm{h}_{\max }=\mathrm{H}_{\max } / \mathrm{H}_{\mathrm{c} 2}\right)$ at which the maximum in $\mathrm{F}_{\mathrm{p}}\left(\mathrm{F}_{\mathrm{pmax}}\right)$ occurs is lower in all existing APC wires. In optimized conventional wire $F_{p}(H)$ is proportional to $h(1-h)$, giving $h_{\max }=0.5$, while in optimized APC wire with $\mathrm{Nb}$ pins, $h_{\max } \sim 0.25$. Although the peak in $F_{p}$ can be moved to higher reduced fields by decreasing the pin size (thus increasing the pin number density), the magnitude of $F_{p}$ is also reduced, partly due to an accompanying decrease in $\mathrm{H}_{\mathrm{c} 2}$ [2], [6] caused by the proximity effect. Since many applications demand high critical current density $\left(\mathrm{J}_{\mathrm{c}}\right)$ at high fields, it is desirable to move $F_{\text {pmax }}$ to higher fields in APC wires.

Recently, Cooley et al. [7] proposed that magnetic pinning is the dominant pinning mechanism in both APC and conventional $\mathrm{Nb}-\mathrm{Ti}$. In the context of the magnetic pinning model, both $\mathrm{F}_{\mathrm{pmax}}$ and $\mathrm{h}_{\max }$ are governed by the pin proximity length $\left(\xi_{\mathrm{N}}\right)$, given by

$$
\xi_{N}(T)=\left(\hbar v_{F} \ell / 6 \pi k_{B} T\right)^{1 / 2}
$$

Manuscript received August 27, 1996.

This work was supported in part by the U.S. Department of EnergyDivision of High Energy Physics.

$$
\ell=v_{F} m / n e^{2} \rho
$$

where $\hbar$ is the modified Planck constant, $v_{F}$ is the Fermi velocity, $k_{B}$ is Boltzmann's constant, $\ell$ is the electron mean free path, $m$ is the electron rest mass, $n$ is the number of free electrons per unit volume and $\rho$ is the resistivity.

A key prediction of the magnetic pinning model is that the maximum elementary pinning force $\left(f_{p}\right)$ should occur for a pin thickness of $\sim \xi_{N}$. The maximum bulk pinning force is then the best compromise between getting a high $\mathrm{f}_{\mathrm{p}}$ and a high $\mathrm{n}_{\mathrm{p}}$, this condition occurring when the thickness is $-\xi_{N} / 3$. Thus, the number density of pins $\left(n_{p}\right)$ at optimum thickness and consequently $h_{\max }$, are determined solely by the electronic properties of the pin material. Since $\xi_{N}(\alpha-T i)$ is less than $\xi_{N}(\mathrm{Nb}), \mathrm{h}_{\max }$ is higher for $\alpha-\mathrm{Ti}$ pins than for $\mathrm{Nb}$ pins. The fact that this is observed experimentally suggests that alloyed $\mathrm{Nb}$ pins will exhibit increased values of $h_{\max }$.

In order to test these predictions, we fabricated APC composites with alloyed $\mathrm{Nb}$ pins, the aims being (1) to reduce the pin proximity length by shortening the electron mean free path and (2) to use a Nb-rich composition to allow for comparison with already existing APC composites made with pure $\mathrm{Nb}$ pins. The second point is particularly important when considering that pins with crystal structures other than the body centered cubic (bcc) structure of $\mathrm{Nb}$ can produce markedly different nanostructures. Both $\mathrm{Nb} 7.5$ wt.\% Ta (Nb7Ta) and $\mathrm{Nb} 10$ wt.\% W (Nb10W) form bcc substitutional solid solutions, exhibit room temperature strain hardening characteristics that are similar to $\mathrm{Nb} 47 \mathrm{wt} \% \mathrm{Ti}$ (Nb47Ti), and have proximity lengths that are significantly shorter, $30 \%$ and $60 \%$ respectively, than that of pure $\mathrm{Nb}$. Hence, they make good candidates for artificial pins.

\section{EXPERIMENTAL PROCEDURE}

Pin proximity lengths were calculated from (1) and (2) using the resistivities of $0.23 \mathrm{~mm}$ diameter wires measured at $10 \mathrm{~K}$. The pin resistivities were measured in a variable temperature cryostat using a current of $100 \mathrm{~mA}$. Although our values of $\xi_{N}$ are higher than those established by Cooley et al., we make no attempt in this paper to correct for the simple classical expressions of (1) and (2).

Table I summarizes the fabrication details for the three APC composites, including the number of pins $\left(N_{p}\right)$ and filaments $\left(\mathrm{N}_{\mathrm{f}}\right)$ and the extrusion temperatures. The Nb-pin APC composite was fabricated using a rod-bundling process 

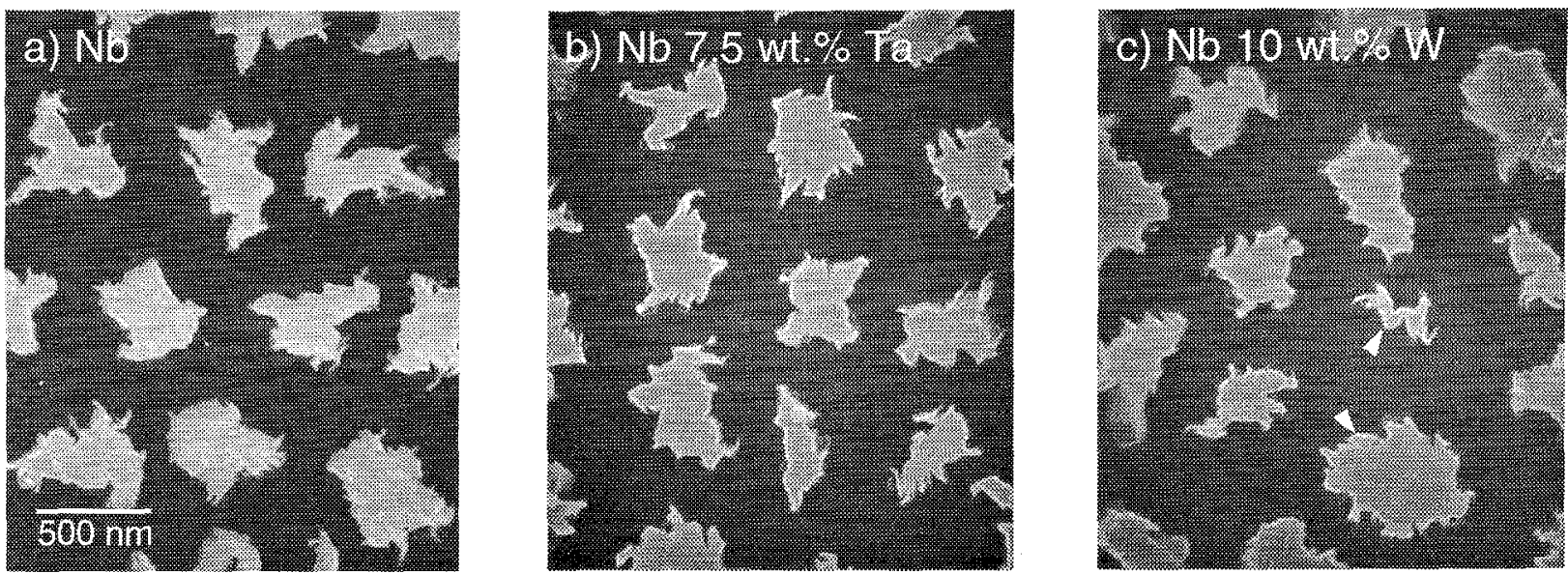

Fig. 1. FESEM secondary-electron images of the a) $\mathrm{Nb}$, b) $\mathrm{Nb} 7 \mathrm{Ta}$ and c) $\mathrm{Nb} 10 \mathrm{~W}$ pinning arrays at a nominal pin diameter of $\sim 400 \mathrm{~nm}$. The wire samples were etched lightly with a mixture of $25 \% \mathrm{HNO}_{3}, 25 \% \mathrm{HF}$ and $50 \% \mathrm{H}_{2} \mathrm{O}$. Examples of sausaged Nb10W pins are indicated by the arrows in Fig. Ic.

described previously [1], [8]. It contained 24.4 vol.\% of pins and produced very high $\mathbf{J}_{\mathrm{c}}$ values in fields up to $6 \mathrm{~T}$, including a record $\mathrm{J}_{\mathrm{c}}(5 \mathrm{~T}, 4.2 \mathrm{~K})$ of $4600 \mathrm{~A} / \mathrm{mm}^{2}$.

The alloyed Nb-pin APC composites were fabricated by the rod-in-tube method first described in [9], in which a rod of the pin material is inserted into a hole drilled into a rod of $\mathrm{Nb}-\mathrm{Ti}$. In our case the pin diameter was $1 / 2$ that of the $\mathrm{Nb} 47 \mathrm{Ti}$ rod, thus giving a pin volume fraction of $25 \%$. Each $\mathrm{Nb} 47 \mathrm{Ti} /$ alloyed $\mathrm{Nb}$-pin composite was canned in $\mathrm{Cu}$ and extruded at $\sim 650^{\circ} \mathrm{C}$ using an area reduction ratio of 10 . The extruded wires were drawn, cut lengthwise into 91 filaments and the $\mathrm{Cu}$ was etched off. The filaments were stacked and extruded under the same conditions. The stack and extrusion sequence was followed twice more with 91 and 55 filaments, the final extrusion being made at $\sim 250^{\circ} \mathrm{C}$. The Nb7Ta-pin wire was drawn through a hexagonally shaped die at $1.1 \mathrm{~mm}$ and 7 filaments were restacked and canned in a $\mathrm{Cu}$ tube, the end product being a wire containing 7 superconducting filaments, each filament containing $91 \times 91 \times 55$ pinning centers. The Nb10W-pin composite was also designed to be a 7 filament composite, however, during its final extrusion only the front section of the composite billet extruded uniformly and the small portion of good quality wire that resulted had to be drawn down as a monofilament. Each composite was cold drawn to various diameters down to 0.08

TABLE I

APC COMPOSITE FABRICATION DETAILS

\begin{tabular}{ccccc}
\cline { 2 - 5 } & \multicolumn{4}{c}{ Stack No./Extrusion Temp. } \\
\cline { 2 - 5 } & $1 / 650^{\circ} \mathrm{C}$ & $2 / 650^{\circ} \mathrm{C}$ & $3 / 250^{\circ} \mathrm{C}$ & $4 / \mathrm{RT}^{\mathrm{b}}$ \\
\hline Pin material & $\mathrm{N}_{\mathrm{p}}$ & $\mathrm{N}_{\mathrm{f}}$ & $\mathrm{N}_{\mathrm{f}}$ & $\mathrm{N}_{\mathrm{f}}$ \\
\hline $\mathrm{Nb}[1]$ & 31 & 127 & 55 & 7 \\
$\mathrm{Nb} 7.5 \mathrm{wt} \% \mathrm{Ta}^{\mathrm{a}}$ & 91 & 91 & 55 & 7 \\
$\mathrm{Nb} 10 \mathrm{wt} . \% \mathrm{~W}^{\mathrm{a}}$ & 91 & 91 & 55 & $\ldots$ \\
\hline${ }^{\mathrm{a}}$ These composites were manufactured via the rod-in-tube method [9] and \\
received an extrusion prior to the first restack. \\
b ${ }^{\mathrm{b}}$ These composites were cold draw stacks.
\end{tabular}

mm. Vickers microhardness measurements were made on transverse wire cross sections using $200 \mathrm{~g}$ or $1000 \mathrm{~g}$ loads applied for $15 \mathrm{~s}$.

Transport critical current $\left(\mathrm{I}_{\mathrm{c}}\right)$ measurements were made at $4.2 \mathrm{~K}$ with the magnetic field applied perpendicular to the wire axis. The voltage tap spacing was $33 \mathrm{~cm}$ and a $10^{-14} \Omega$ $\mathrm{m}$ criterion applied over the entire wire cross section was used to determine $I_{c}$. $J_{c}$ was calculated by dividing $I_{c}$ by the superconductor cross-sectional area. Copper-tosuperconductor ratios were determined by weighing, etching the $\mathrm{Cu}$ off and reweighing.

\section{RESULTS}

Table I lists the measured $10 \mathrm{~K}$ resistivities and calculated $\ell$ and $\xi_{N}$ values for each pin material. The $\xi_{N}$ values for $\mathrm{Nb}$, $\mathrm{Nb} 7 \mathrm{Ta}$ and $\mathrm{Nb} 10 \mathrm{~W}$ and pure $\mathrm{Ti}$ are 83, 59, 32 and $32 \mathrm{~nm}$, respectively.

Figs. 1a, b and $\mathrm{c}$ show field emission scanning electron microscope (FESEM) secondary-electron images of the $\mathrm{Nb}$, Nb7Ta and Nb10W composites, respectively, at $d_{p} \sim 400 \mathrm{~nm}$. The nominal pin diameter $\left(d_{p}\right)$ is defined by:

$$
d_{p}=d_{w} /\left(N_{p} / V_{f}(1+R)\right)^{1 / 2}
$$

where $d_{w}$ is the wire diameter, $N_{p}$ is the number of pins, $V_{f}$ is the volume fraction of pins and $\mathrm{R}$ is the $\mathrm{Cu}$-to-superconductor ratio. In each case, the pin shape was irregular but the

TABLE II

ARTIFICIAL PIN ELECTRONIC PROPERTIES AT $10 \mathrm{~K}$

\begin{tabular}{|c|c|c|c|}
\hline Pin material & $\rho_{0}(\mu \Omega-\mathrm{cm})$ & $\ell(\mathrm{nm})$ & $\xi_{N}(n m)$ \\
\hline $\mathrm{Nb}$ & 0.567 & 53 & 83 \\
\hline $\mathrm{Nb} 7.5 \mathrm{wt} . \% \mathrm{Ta}$ & 1.11 & 27 & 59 \\
\hline $\mathrm{Nb} 10 \mathrm{wt} . \% \mathrm{~W}$ & 3.67 & 7.7 & 32 \\
\hline $\mathrm{Ti}$ & 5.61 & 6.1 & 32 \\
\hline
\end{tabular}




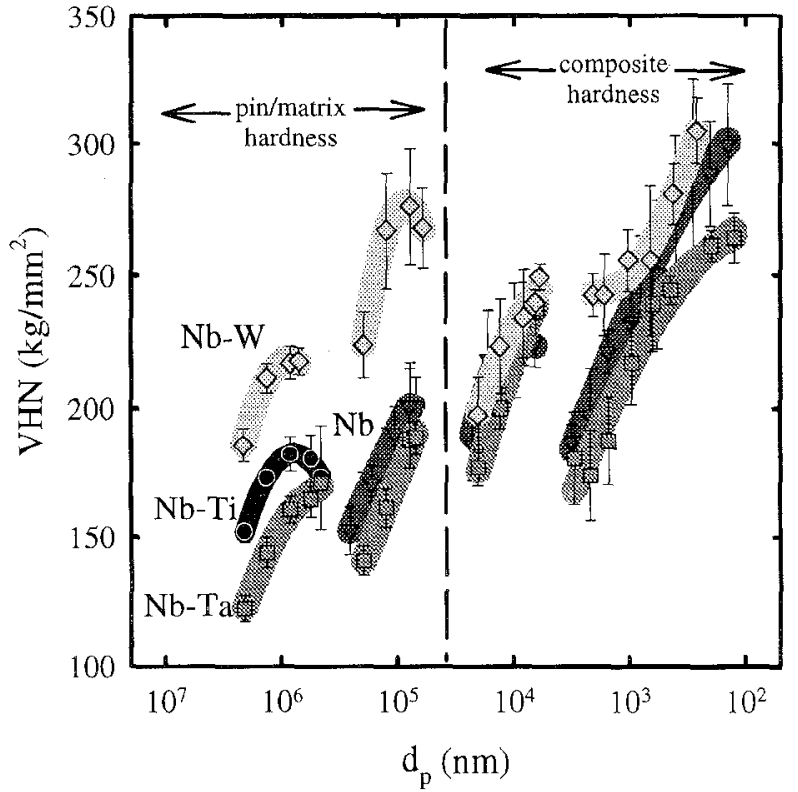

Fig. 2. Vickers microhardness versus nominal pin diameter for the three composites. Data from $5 \mathrm{~mm}>\mathrm{d}_{\mathrm{p}}>50 \mu \mathrm{m}$ reflect the pin or $\mathrm{Nb}-\mathrm{Ti}$ matrix hardness while those from $50>d_{p}>100 \mathrm{~nm}$ reflect the overall composite hardness. Breaks between the data sets indicate where the extrusions occurred.

designed hexagonal pin arrangement was still clear. The only noticeable difference between the three pin arrays is that some sausaging of the Nb10W pins occurred, as shown in Fig. 1c. This may be partially the consequence of insufficient workrecrystallization cycles for the Nb10W alloy, which had a different origin from the $\mathrm{Nb}$ and $\mathrm{Nb} 7 \mathrm{Ta}$.

Fig. 2 shows the Vickers microhardness as a function of the nominal pin diameter. At larger pin diameters $\left(5 \mathrm{~mm}>\mathrm{d}_{\mathrm{p}}\right.$ $>50 \mu \mathrm{m})$, the pin hardness can be determined, but at smaller diameters $\left(50 \mu \mathrm{m}>d_{p}>100 \mathrm{~nm}\right)$ only the composite hardness can be measured. Breaks in the data indicate where the warm extrusions occurred. The strain-hardening characteristics of the $\mathrm{Nb}$ and Nb7Ta pins and the Nb47Ti matrix are very similar; the hardness increases with cold drawing strain but drops off during extrusion. The Nb10W pins strain harden at a rate similar to the other pins but do not recover during extrusion. As a result, the overall strain hardening rate is higher for both the Nb10W pins and the $\mathrm{Nb} 10 \mathrm{~W} / \mathrm{Nb} 47 \mathrm{Ti}$ composite.

Figs. 3a-c plot the bulk flux pinning force $F_{p}=J_{c} \times \mu_{0} H$ versus applied field for the $\mathrm{Nb}, \mathrm{Nb} 10 \mathrm{~W}$ and $\mathrm{Nb} 7 \mathrm{Ta}$ pin composites, respectively. The development of $\mathrm{F}_{\mathrm{p}}(\mathrm{H})$ with decreasing pin diameter shown for the $\mathrm{Nb}$ composite in Fig. $3 \mathrm{a}$ is similar to that described previously for a composite of identical composition but fabricated using different processing parameters [6]. As the nominal pin diameter drops below $100 \mathrm{~nm}$, a low field peak in $\mathrm{F}_{\mathrm{p}}(\mathrm{H})$ emerges, reaching a maximum value of $32 \mathrm{GN} / \mathrm{m}^{3}$ at $2.5 \mathrm{~T}$ for $\mathrm{d}_{\mathrm{p}} \sim 40$ $\mathrm{nm}$. When the pin size is further reduced, the peak position shifts to higher fields, but the magnitude declines. A similar development of $F_{p}\left(H, d_{p}\right)$ is shown for the Nb7Ta pin composite in Fig. $3 \mathrm{~b}$. In this case $\mathrm{F}_{\mathrm{pmax}}$ reached $25 \mathrm{GN} / \mathrm{m}^{3}$, but at higher field $(3 \mathrm{~T})$ and smaller $\mathrm{d}_{\mathrm{p}}(35 \mathrm{~nm})$. It should be noted that low field flux jumps in the wires with $d_{p}>35 \mathrm{~nm}$ may have prevented measurement of the true $\mathrm{F}_{\mathrm{pmax}}$.

The development of $F_{p}(H)$ over the interval $d_{p}=82-32 \mathrm{~nm}$ in the NbloW-pin composite (Fig. 3c) differs qualitatively from that observed for the pure $\mathrm{Nb}$ and $\mathrm{Nb} 7 \mathrm{Ta}$ pin composites. It bears a closer resemblance to the development of $F_{p}(H)$ seen in conventionally processed $\mathrm{Nb} 47 \mathrm{Ti}$ [4] during the drawing strain at large pin size, following the last precipitation heat treatment. As in the other APC composites, a low field peak in $F_{p}(H)$ develops at large $d_{p}$, but the optimum curve is not reached, at least until $d_{p}=32 \mathrm{~nm}$ (the smallest wire tested). The peak value of $F_{p}, 15 \mathrm{GN} / \mathrm{m}^{3}$, appears to still be rising with decreasing $d_{p}$ because there is a comparatively larger increase of $F_{p}$ with changing $d_{p}$ at this size than is seen in Figs. $3 a$ and $3 b$ near the optimum value of $d_{p}$

\section{Discussion}

As expected, the proximity length of the $\mathrm{Nb}$ pins decreased with alloying. The proximity lengths of Nb7Ta $(59 \mathrm{~nm})$ and Nb10W (32 nm) are 30\% and 60\% shorter, respectively, than that of pure $\mathrm{Nb}(83 \mathrm{~nm})$. Nb10W has the same $\xi_{\mathrm{N}}$ as that measured for pure $\mathrm{Ti}[10]$, but $\xi_{\mathrm{N}}$ for $\alpha$-Ti is likely even shorter because it is alloyed with 5 at.\% $\mathrm{Nb}$ [5].

The trends seen in the $\mathrm{F}_{\mathrm{p}}\left(\mathrm{H}, \mathrm{d}_{\mathrm{p}}\right)$ curves of Fig. 3 are qualitatively consistent with the magnetic pinning model. As the pin proximity length was reduced, the value of $h_{\max }$ increased and $F_{\text {pmax }}$ occurred at smaller nominal pin diameters. Stronger validation of the magnetic pinning model may come with the identification of $h_{\max }$ and $F_{\text {pmax }}$ in the Nb10W-pin composite, which unfortunately, was not possible in this experiment due to the fabrication difficulties discussed above.

APC fabrication improvements are still being made. Our recent work on pure Nb pin APC composites [1] produced large increases $(-40 \%)$ in $\mathrm{F}_{\mathrm{p} \max }$ with little change in $\mathrm{h}_{\max } . \mathrm{Nb}$ 7.5 wt. \% Ta seems almost identical to Nb in hardness, workhardening and fabricability. However, the Nb10W was markedly worse, undoubtedly because $\mathrm{W}$ has a smaller atomic radius $(0.142 \mathrm{~nm})$ than both $\mathrm{Nb}$ and $\mathrm{Ta}(0.147 \mathrm{~nm})$, causing the increased work-hardening shown in Fig. 2. However, the $32 \mathrm{~nm}$ limit placed on the Nb10 $\mathrm{W}$ pin size in this experiment should not be considered as a severe obstacle to fabricating wires with smaller nominal pin size. Composite break-up during the final extrusion may have been more a result of the billet design and extrusion parameters not being optimized for the higher overall $\mathrm{Nb} 47 \mathrm{Ti} / \mathrm{Nb} 10 \mathrm{~W}$ composite hardness, rather than as a direct consequence of the pin/matrix hardness disparity. This hypothesis is supported by the fact that the Nb10W pin composite drew well following the final extrusion; the pin sausaging seen in Fig. 1c did not adversely 

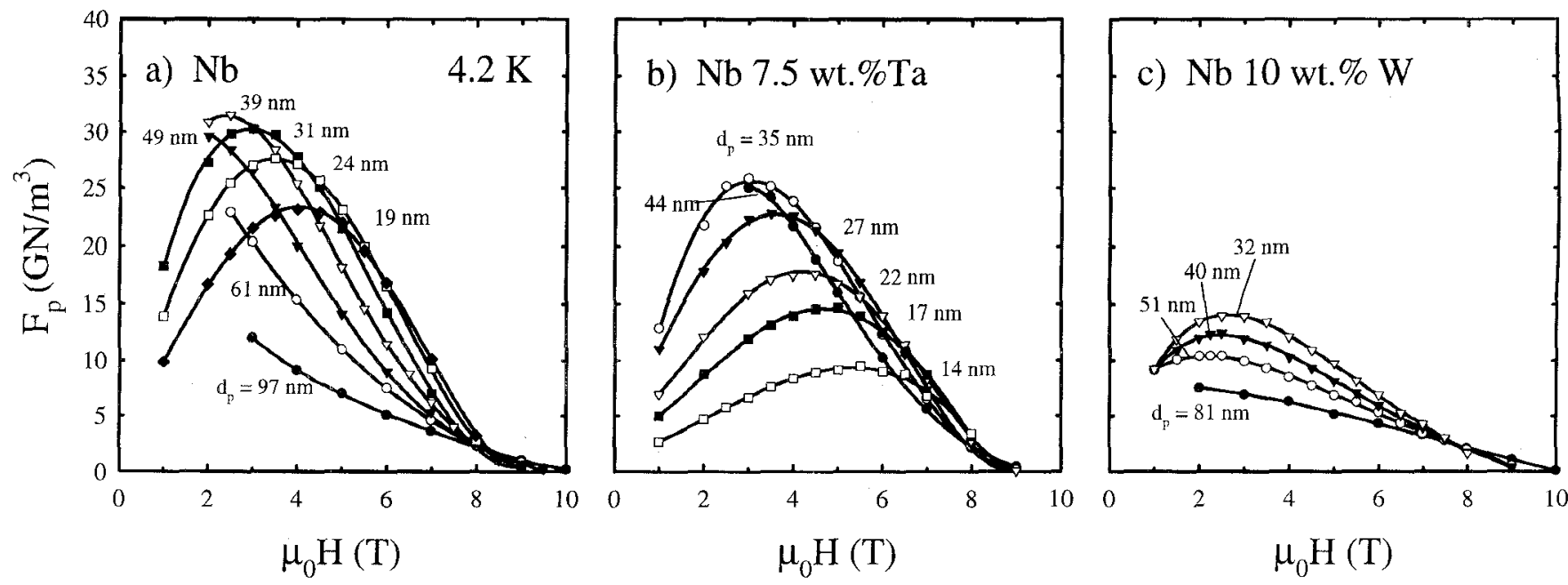

Fig. 3. Bulk flux pinning force versus applied field for the a) $\mathrm{Nb}$, b) Nb7Ta and c) Nb10W-pin APC composites at $4.2 \mathrm{~K}$. Note that wires with $\mathrm{d}_{\mathrm{p}}<32 \mathrm{~nm}$ were not fabricated for the $\mathrm{Nb} 10 \mathrm{~W}$-pin composite due to fabrication difficulties.

affect its drawability. Future experiments will investigate $\mathrm{Nb} 10 \mathrm{~W}$-pin APC wires in more detail, especially in the lower limit of $d_{p}$.

\section{CONCLUSIONS}

APC Nb $47 \mathrm{wt} . \%$ Ti wires containing 25 vol.\% of alloyed $\mathrm{Nb}$ pins were fabricated to evaluate the effect of the pin proximity length $\xi_{\mathrm{N}}$ on the flux pinning properties. The proximity length of pure $\mathrm{Nb}, 83 \mathrm{~nm}$, decreased to $59 \mathrm{~nm}$ and $32 \mathrm{~nm}$ when alloyed with $7.5 \mathrm{wt} . \% \mathrm{Ta}$ and $10 \mathrm{wt} . \% \mathrm{~W}$, respectively. The field and pin thickness dependence of the $F_{p}$ curves qualitatively support the magnetic pinning model; as $\xi_{\mathrm{N}}$ decreased, the field and pin thickness at which the maximum $F_{p}$ occurred increased and decreased, respectively. Excessive hardening of the Nb10W-pin composite, an adverse effect of the tungsten alloying addition, caused composite fabrication difficulties and prevented wires with $\mathrm{d}_{\mathrm{p}}<32 \mathrm{~nm}$ from being fabricated. Future work will investigate the role of $\xi_{\mathrm{N}}$ in greater detail.

\section{ACKNOWLEDGMENTS}

We gratefully acknowledge P. Lee, A. Gurevich, E. Kadyrov, W. Starch, A. Squitieri, M. Pelletier, M. Schlinkert and A. Lindner for discussions and experimental assistance and P. Jablonski and P. Morris with Teledyne Wah Chang for donating the $\mathrm{Nb}-\mathrm{Ti}$ and $\mathrm{Nb} 7 \mathrm{Ta}$ rods. The scanning electron microscopy was partially supported through the Integrated Microscopy Resource, Madison, WI which is supported through a NIH Biomedical Research Technology Grant.

\section{REFERENCES}

[1] R.W. Heussner, J.D. Marquardt, P.J. Lee and D.C. Larbalestier, to appear Appl. Phys. Lett., 1997.

[2] K. Matsumoto, H. Takewaki, Y. Tanaka, O. Miura, K. Yamafuji, K. Funaki, M. Iwakuma and T. Matsushita, Appl. Phys. Lett., vol. 64, 1994, pp. 115-117.

[3] C. Li and D.C. Larbalestier, Cryogenics, vol. 27, 1987, pp. 171-177.

[4] C. Meingast, P.J. Lee and D.C. Larbalestier, J. Appl. Phys., vol. 66, 1989 , pp. 5962-5970.

[5] P. J. Lee and D.C. Larbalestier, Acta. Metall, vol. 35, 1987, pp. 2526 2536.

[6] R.W. Heussner, C.B. Nunes, P.J. Lee, D.C. Larbalestier and P.D. Jablonski, J. Appl. Phys., vol. 80, 1996, pp. 1640-1646.

[7] L.D. Cooley, P.J. Lee and D.C. Larbalestier, Phys. Rev. B, vol. 53, 1996, pp. 6638-6652.

[8] R.W. Heussner, P.D. Jablonski, P.J. Lee and D.C. Larbalestier, IEEE Trans. Appl. Supercond., vol. 5, 1995, pp. 1705-1708.

[9] B. A. Zeitlin, M.S. Walker and L. R. Motowidlo, United States Patent No. 4,803,310 (Feb 7, 1989)

[10] C.B. Nunes, unpublished work. 